\title{
ANÁLISE INSTITUCIONAL E O PROCESSO DE CONSTRUÇÃO DE CONHECIMENTO: A QUESTÃO DA IMPLICAÇÃO
}

INSTITUTIONAL ANALYSIS AND THE CONSTRUCTION OF KNOWLEDGE: THE IMPLICATION'S QUESTION

\author{
ANÁLISIS INSTITUCIONAL Y EL PROCESO DE CONSTRUCCIÓN DE CONOCIMIENTO: LA \\ CUESTIÓN DE LA IMPLICACIÓN
}

João Batista Martins*

\begin{abstract}
RESUMO
Este trabalho tem como perspectiva, a partir do campo da análise institucional, apresentar a noção de implicação como uma dimensão que nos permite compreender a intervenção institucional em sua complexidade. Tal noção nos auxilia a compreender os interstícios da intervenção, seus meandros, seus rumores. Ela se circunscreve sob duas dimensões: a que diz respeito aos processos institucionais inconscientes que possibilitam ao analista estar ali; e a que diz respeito ao próprio analista, que se vê implicado em sua prática institucional. $\mathrm{O}$ processo analítico que se desenha nesee encontro possibilita a construção de um conhecimento implicado e compartilhado - uma produção de conhecimento tanto do analista como da instituição -, processo de construção de conhecimento que se dá sob o signo da alteração.
\end{abstract}

Palavras-chave: Implicação. Construção de conhecimento. Análise Institucional.

\section{ABSTRACT}

This work has the perspective. from the field of institutional analysis, introduce the notion of implication as a dimension that allows us to understand the institutional intervention in its complexity. This notion helps us understand the interstices of intervention, their intricacies, their rumors. It is limited under two dimensions: one that concerns the institutional processes unconscious that allow the analyst to be there. Another dimension concerns the analyst himself, who finds himself involved in institutional practice. The analytical process that draws on this date allows the construction of a knowledge involved and shared-a knowledge of both the analyst and the institution-building process of knowledge that takes place under the sign of the change.

Keywords: Implication. Knowledge construction. Institutional analysis

\footnotetext{
* Docente do Departamento de Psicologia Social e Institucional, Universidade Estadual de Londrina Programa de Pós-Graduação em Psicologia - UNESP/Assis. Email: jbmartin@sercomtel.com.br
} 


\section{RESUMEN}

Este trabajo tiene la perspectiva desde el campo del análisis institucional, introducir la noción de implicación como una dimensión que nos permite comprender la intervención institucional en su complejidad. Esta noción nos ayude a entender los intersticios de la intervención, sus complejidades, sus rumores. Ella es limitada en dos dimensiones: una que se refiere a los procesos institucionales desconocen que permite al analista estar allí. Otra dimensión refiere a la analista, que se encuentra involucrado en la práctica institucional. El proceso analítico que se basa en esta fecha permite la construcción de un conocimiento participan y comparten un conocimiento del analista y el proceso de institucionalización del conocimiento que se desarrolla bajo el signo del cambio.

Palabras clave: Implicación. Construcción de conocimiento. Análisis institucional

\section{INTRODUÇÃO}

T

omando como ponto de partida o desenvolvimento da psicologia, podemos dizer que ela, enquanto um campo científico que nasceu na segunda metade do século XIX, na Europa, numa sociedade capitalista industrial, se desenvolveu através do embate de alguns paradigmas inconciliáveis (Figueiredo, 1991, 1993). Apesar de essa disciplina se estruturar a partir de uma unidade - unidade esta que se subsidiou nos parâmetros científicos da época (os das ciências naturais) -, ela se estabeleceu no universo da ciência muito mais como um discurso ideológico, uma vez que se constituiu como instrumento das necessidades da sociedade em que nasceu, com o objetivo de selecionar, orientar, adaptar e racionalizar, visando, em última instância, a um aumento da produtividade (Patto, 1984).

Cabe registrar, no entanto, que, ao longo dos anos, novos caminhos foram se circunscrevendo para essa ciência, com caminhos não tão próximos ao modelo das ciências naturais. Assim, as influências das correntes das ciências sociais mais críticas tiveram seu efeito sobre a prática do psicólogo e sua produção teórica. Dentro desse contexto, localizamos o movimento da análise institucional ${ }^{1}$ como um campo extremamente importante, uma vez que abriu novos caminhos para a prática $p s i$ nas instituições.

A seguir, apresentamos algumas ideias que localizam a emergência da análise institucional, estabelecendo um novo campo de coerência, no âmbito das ciências humanas, bem como uma discussão teórica acerca do processo de produção

1 Cabe esclarecer que, ao nos referirmos ao movimento de análise institucional, estamos nos remetendo ao movimento que se consolidou na França, após a Segunda Guerra Mundial, e que teve como expoentes autores como Lapassade e Lourau (1972). 
de conhecimento, que daí se desdobra, tendo como ponto de partida algumas noçôes desenvolvidas no campo da análise institucional, mais especificamente a noção de implicação.

\section{DA ANÁLISE INSTITUCIONAL}

Segundo Hammouti (2002), podemos localizar a emergência da teoria da análise institucional após a Segunda Guerra Mundial, a partir das experiências de psiquiatras e psicólogos que trabalhavam com doentes mentais nos hospitais psiquiátricos. Essas atividades se apoiavam no reconhecimento da dimensão política implicado no tratamento psiquiátrico, o que trouxe uma mudança fundamental na abordagem dos pacientes, uma vez que a cura passou a ser considerada não mais a partir das relações terapêuticas estabelecidas entre médico/psiquiatra e o doente, mas da instituição, de seu funcionamento organizacional. Lourau (1996) denomina essa fase de humanização das relações hospitalares como empírica, circunscrita no contexto da ocupação nazista e que se baseava numa concepção militante e política marxista contra qualquer forma de opressão, inclusive na relação psiquiatra-doente mental.

Após a Segunda Guerra Mundial, ainda segundo Hammouti (2002), novas técnicas foram importadas dos Estados Unidos, as psicoterapias de grupo. A introdução do psicodrama de Moreno vai desempenhar um papel importante, assim como as técnicas de "psicoterapia ocupacional" (ergoterapia, socioterapia, técnicas ativas, técnicas Freinet).

$\mathrm{Na}$ esteira de Moreno, falava-se em "revolução sociométrica": a terapia de grupo implica a constituição de uma comunidade terapêutica. Aparecem as "reuniōes de síntese", os "coletivos terapêuticos", as "oficinas", as "reuniōes de pavilhão", todo um tecido de encontros que dão uma nova forma à

organização hospitalar e que transformam as relações sociais na instituição. (Hess \& Savoye, 1993, 11-12).

Lourau (1996) caracterizou esse momento do movimento como ideológico, que se caracterizou pela ressocialização dos doentes, por meio da nova organização da vida em grupo, no interior do hospital. A expressão psicoterapia institucional aparece pela primeira em Daumezon e Koechlin (1952), no artigo La psichoterapie institutionnelle française contemporiane (publicado nos Anais Portugueses de Psiquiatria, n. 4).

O momento denominado por Lourau (1996) como teórico é marcado pelo processo de teorização dos fenômenos institucionais. Segundo Hammouti (2002), 
No hospital psiquiátrico de Saint-Alban e na Clínica de La Borde (Cour-Cheverney), começaram a ser repensadas as práticas de psicoterapia institucional; foi introduzida a dimensão inconsciente da instituição, houve uma mudança no olhar teórico sobre as práticas e interrogou-se o sentido da instituição de novas formas sociais da terapia. Nesse momento de desenvolvimento teórico, foram elaborados os principais conceitos da análise institucional: analisador, transversalidade, transferência e contratransferência institucionais, grupo-sujeito e grupo-objeto. Esses conceitos aparecem nas publicações de 1964 a 1965 (em revistas como La Revue de Psichothérapie Institucionnelle e Recherches, as quais são reproduzidas no livro de F. Guattari Psychanalyse et transversalité). (Hammouti, 2002, p. 21).

Lourau, em 1970, publicou A análise institucional (Lourau, 1996), mobilizando modelos interpretativos estritamente dialéticos, estabelecendo alguns parâmetros teóricos e práticos para a pesquisa e intervenção institucionalista. Em 1972, junto com Georges Lapassade, escreve Chaves da sociologia (Clefspour la sociologie), um livro que vai contribuir para a constituição de um novo campo de coerência científico, uma vez que rompe com as orientações dominantes da sociologia de seu tempo: eles ambicionam refundar a sociologia sobre as novas bases, tendo a intervenção - a análise institucional - como sua pedra fundamental.

Entretanto, em suas proposições, não estabelecem, com relação à questão da implicação, um avanço significativo. Podemos verificar que os autores fazem um esclarecimento do conceito e o colocam no lugar dos "instrumentos de análise" (distância, implicação, transferência) enunciados dentro do $A$ análise institucional, uma formulação condensada na expressão "implicações no objeto estudado (implicações afetivas, ideológicas, políticas" (Lapassade \& Lourau, 1972, p. 171), ideia que será mantida ao longo do desenvolvimento teórico até 1983, como veremos mais à frente.

Vale lembrar que, para estabelecer a nova acepção de implicação, eles se apoiam não mais nas experiências socioanalíticas, mas no "método que procure ultrapassar os riscos de uma tenacidade pura, dando ênfase aos objetivos e implicaçōes do entrevistador" (Lapassade \& Lourau, 1972, p. 43), a saber, o método marxista, aquele proposto por Mao Tsé-Tung, no qual a implicação dos pesquisadores é ressaltada: "A implicação, longe de ser um obstáculo, é uma condição da pesquisa" (Lapassade \& Lourau, 1972, p. 47). Cabe registrar, no entanto, que a implicação apresentada nessa obra - Chaves da sociologia - expressa muito mais um engajamento pessoal, de caráter militante do sociólogo que se vê envolvido "na prática da luta de classes e da experiência científica de seu tempo" (conforme formulação de Mao Tsé-Tung, apresentada em Lapassade \& Lourau, 1972, p. 47) $)^{2}$ o que nos leva a reconhecer a dimensão política da análise institucional.

\footnotetext{
2 O que será qualificado mais tarde por Lourau como sobreimplicação. Ver Lourau, 2004b: 186-198).
} 
A temática da implicação será revisitada em 1983, em um número dedicado ao tema na revista Pour, de onde destacamos os trabalhos de Lourau, Genèse du concept d'implication, e de Ardoino (1983), Polysémie de l'implication, que apresentaremos em seguida.

\section{DA IMPLICAÇÃO}

Ardoino vai localizar a questão da implicação reconhecendo sua importância para a consolidação da análise institucional, cuja elaboração teórica estava sendo efetivada por um grupo de pesquisadores da Maison de Sciences de l'Homme.

Num primeiro momento, esse autor estabelece uma distinção:

Lembramos que é necessário distinguir [...] entre as implicações libidinais, identificadas pelos psicólogos, examinando as pulsōes, os fantasmas, as tendências, as motivaçōes, a memória dos indivíduos como o inconsciente e as implicaçôes institucionais, sócio-econômicopolíticas, ligadas às posiçôes sociais, aos status, aos pertencimentos, às ideologias, melhor analisadas pela sociologia. (Ardoino, 1983, p. 19).

Para esse autor, a implicação se revela muito mais como um modo de ser, opaco à consciência, entendendo a noção de implicação num sentido psicológico, a partir da qual os analistas institucionais puderam fazer "do conhecimento e da análise da implicação um pretexto para uma démarche crítica, recusando sem pena os behaviorismos e, mais geralmente, o imperialismo das abordagens quantitativas ou dos modelos positivistas". (Ardoino, 1983, p. 19).

Ardoino reconhece nesse texto que a noção de implicação ainda não tinha sido trabalhada suficientemente, mas as interrogações a que ela nos conduz situam-se sobre um plano mais epistemológico do que metodológico, uma vez que tal noção aparece como

[...] um modo particular de conhecimento ligado a um modo específico de ser, caracterizado pela existência. Dito de outra forma, objeto possível e desejável de análise, porque modo de ser, a implicação constitui outro modo especial de produção de conhecimento onde ela se torna parte integrante. (Ardoino, 1983, p. 20).

Já o texto de Lourau (1983) traça os campos disciplinares que, de uma certa forma, contribuíram para a elaboração do conceito de implicação. Trata-se de um percurso que envolve a fenomenologia, a psicanálise, a etnologia e a história das micro e macrofísicas contemporâneas, especialmente quando essas disciplinas, a partir de seus pressupostos teóricos, colocam em questão a relação sujeito $\mathrm{x}$ objeto. 
Após traçar o percurso da noção de implicação no campo da análise institucional, Lourau propóe, ainda que de modo provisório, o seguinte esquema para estabelecer uma classificação que nos permite fazer uma análise da implicação:

Implicações primárias:

a. implicações do pesquisador-prático, em relação ao seu objeto de pesquisa/ intervenção

b. implicação em relação à instituição de pesquisa ou outra instituição de pertencimento, e em relação à equipe de pesquisa/intervenção

c. implicação em relação ao comando social e às demandas sociais

d. Implicaçõos secundárias:

e. implicações sociais, históricas, dos modelos utilizados (implicação epistemológica)

f. implicações dentro da escritura ou em todo outro meio que serve para exposição da pesquisa. (Lourau, 1983, p. 17).

Finalizando o texto, Lourau (1983) considera o "vivido", a vida cotidiana, como um elemento que circunscreve as cinco dimensōes descritas:

O vivido não é um mundo à parte, mas a trama da pesquisa como da formação e de todas as nossas atividades, diurnas ou noturnas. Seria, portanto, diminuí-lo, até suprimir toda sua importância, isolá-lo das diversas operações que fazem de toda pesquisa (e não somente da pesquisa-ação) uma série interminável de atos falhos. Somente a análise das implicações permite compreender e transformar relativamente os atos falhos da pesquisa em ciências sociais. (Lourau, 1983, p. 18).

Ardoino se aproxima dessa formulação de Lourau, quando, ao percorrer a etimologia das palavras explicação e implicação, nos sugere que o explicativo nos remete à dimensão espacial, supõe modelos lógicos, físicos ou mecânicos; já a implicação nos remete à dimensão temporal, histórica, às metáforas - psicológicas, sociológicas ou biológicas - ligadas à especificidade do vivente. (Ardoino, 1983, p. 21).

\section{O PAPEL DO ANALISTA INSTITUCIONAL}

Quando um analista institucional entra em cena? Lourau (2004a) nos assinala que o analista institucional entra em cena, ou é convocado, quando a 
sociedade ou as instituiçôes sociais estão em crise. Para Hammoutti (2002), o próprio movimento da análise institucional se valeu das diversas crises sociais para avançar em seus pressupostos e em suas teorizações.

Assim, num primeiro momento, conforme Ardoino e Lourau (1994), a prática dos analistas institucionais era caracterizada por uma intervenção de curta duração, na qual se colocavam em análise vários dispositivos: a análise da demanda, a análise do pagamento, a análise das relaçóes de poder, etc... Ao longo do tempo, especialmente depois de 1986, com o trabalho de Boumard, Hess, e Lapassade (1987), a prática da análise institucional incorpora, em seu corpo teórico, algumas considerações realizadas pela etnologia no que diz respeito à observação participante. Sob essa perspectiva, a intervenção do analista passa a ser mais longa do ponto de vista temporal. Há uma convivência mais estreita entre o analista e o campo em que está intervindo. Nessa situação, a convivência entre o pesquisador/analista e os envolvidos pode levar ao estabelecimento de uma relação sincrética entre eles, no ambiente de pesquisa ou de intervenção.

Considerando que o principal objetivo do analista institucional é o de desvelar os jogos de sentido que perpassam as relações sociais, os valores aí implícitos, a ideologia etc., presentes na instituição e que ele próprio, o analista, é um dos sujeitos que se vê alterado (implicado) pelas relaçôes que ali se estabelecem, o processo de conhecimento (produzido pela ação do analista e no coletivo dos que participam do cotidiano institucional) se realiza a partir do encontro intersubjetivo promovido pela situação institucional.

\subsection{Implicação e processo de construção de conhecimento}

Tal perspectiva vem afirmar a especificidade da prática do analista institucional, não mais através de um objeto empírico constituído - a instituição -, mas através de uma abordagem epistemológica constituinte. Ou seja, quando o analista institucional se insere no campo, ele não só observa, mas também participa com os seus interlocutores nas várias situações sociais que circunscrevem o universo social que está pesquisando. Assim, podemos dizer que o objeto teórico da análise institucional deixa de estar ligado a um espaço cultural ou histórico particular, pois passa a caracterizar-se como uma maneira de olhar o outro e a si mesmo, em relação.

Essa perspectiva rompe com as perspectivas epistemológicas tradicionais à medida que reconhece que o conhecimento se realiza na relação mesma entre sujeito e objeto - na relação intersubjetiva. Isso significa dizer que, no lugar de ter um objeto que se quer objetivo, nós iremos, na verdade, ter um objeto que é ao mesmo tempo sujeito. ${ }^{3}$

3 Palestra Análise institucional: gênese, atualidade e perspectivas proferida, em 1998) na Universidade Federal do Rio Grande do Sul, Faculdade de Psicologia. Porto Alegre. 
Cabe salientar, no entanto, que, no âmbito da pesquisa, os seres vivos, especialmente os humanos, quando submetidos a quaisquer que sejam os determinismos (econômicos, sociais, culturais etc.) que os condicionam e que podem explicar seus modos de funcionamento, têm em si um poder de negação, de contra-estratégia que lhes dá, ao menos em parte, a inteligência desses determinismos e uma certa capacidade de reagir e de adaptar-se, senão de transformá-los. Ardoino denomina essa capacidade de negatricidade, o que significa o reconhecimento de certa opacidade própria dos objetos que estão sob investigação. Ardoino entende negatricidade como "a capacidade que o outro possui sempre de poder desmantelar com suas próprias contra-estratégias aquelas das quais se sente objeto". (Ardoino, Barbier \& Giust-Desprairies, 1998, p. 68). Isso quer dizer que o homem, tanto individual como coletivamente, não é indiferente às produções de saber que lhe concernem e que reagirá diante delas, interferirá constantemente com os dispositivos de análise e de investigação que lhe serão aplicados, perturbando seu funcionamento.

Além disso, do ponto de vista do pesquisador, Ardoino considera que, além de ele não dominar seu objeto, no sentido de controle, em função da negatricidade que lhe é inerente, ele está implicado com ele e nele. Tal perspectiva nos sugere que o processo de construção de conhecimento não se efetiva sob a égide exclusiva de uma determinada racionalidade. Pelo contrário, o conhecer se estabelece a partir de outros vários planos: das motivações mais profundas do pesquisador (inconscientes?), de seus desejos, de suas projeçóes pessoais, de suas identificações, de sua trajetória pessoal etc. Nesse sentido, podemos dizer que a relação entre sujeito e objeto propicia tanto o desvelamento do objeto como o desvelamento do sujeito.

Com a noção de implicação assume-se que o conhecimento produzido no âmbito da análise institucional é da ordem da intersubjetividade, o que significa reconhecer que a produção de conhecimento implica um processo de "negociação" entre as múltiplas referências que compõem o conjunto das representaçôes de cada indivíduo envolvido no processo, ou seja, o conhecimento se produz a partir da heterogeneidade dos sentidos que está implícita nas relações que se estabelecem no campo da pesquisa.

Queremos dizer com isso que a relação entre sujeito e objeto, entendida como um encontro intersubjetivo, requer o reconhecimento de dimensóes que não estão relacionadas nem com os aspectos teóricos, nem com os aspectos metodológicos, que utilizamos na realização de nossas pesquisas. Tais dimensões estão circunscritas pela ordem do psíquico, do desejo, da vontade, que implicam afetos nem sempre "dizíveis" em nosso cotidiano acadêmico, mas que emergem durante a construção do conhecimento. 
Numa perspectiva psicológica, podemos dizer que a heterogeneidade intrínseca na relação entre sujeito e objeto se caracteriza como processo de alteração, já que ela é circunscrita por um jogo de influências mútuas. A interação (alteração) desencadeia jogos próprios das vontades, dos desejos, da angústia, das manifestações de uma vida inconsciente, de um funcionamento imaginário, que suscitam tantas estratégias, resistências, ambivalências, opacidades: expressões de uma negatricidade que permanecem ininteligíveis para um aparato racional. Tal situação, em função de sua complexidade, geralmente, nos leva para os caminhos das incertezas e do inacabamento, condições impensáveis na ótica de uma epistemologia tradicional, cartesiana, positivista.

As perspectivas mencionadas nos abrem a possibilidade de traçar um novo caminho no processo de elucidação dos fenômenos sociais, rompendo com a posição epistemológica desenvolvida ao longo da Modernidade. Podemos dizer que esse rompimento restaura o espaço de sentido de cada participante das relações e nos permite pensar esse espaço restaurado como circunscrevendo o discurso de um sujeito falante, tanto para aquele que se diz pesquisador como para aquele que é olhado como objeto, libertando o homem da sua condição de objeto.

Sob a perspectiva que aqui defendemos, a análise dos fenômenos sociais assume outra dimensão. Para Ardoino (1990),

[...] o tipo de análise em questão não tem mais grande relação com a análise entendida etimologicamente (decomposição, redução do complicado em elementos mais simples). É mais uma sagacidade (perspicácia), vinculada a um processo de acompanhamento numa duração, a intimidade partilhada, donde [...] os exemplos psicanalítico, socioanalítico, etnológico, etnográfico, e até etnometodológico, podem nos dar alguma ideia. (Ardoino, 1990 , p. 38).

Tal perspectiva, tanto para o plano da pesquisa como para o plano das práticas sociais, permite-nos um reconhecimento mais profundo de elementos até então desconsiderados (principalmente no que se refere à pesquisa) sobre os processos relacionais, possibilitando-nos uma reapropriação da experiência pela abertura ao desconhecido, pela disponibilidade para a alteração e, por consequência, para a heterogeneidade, para a escuta do inefável.

Em outro lugar (Martins, 1995), tivemos a oportunidade de assinalar as vicissitudes inerentes à relação sujeito e objeto, em que se apontou a necessidade de reconhecermos a imprevisibilidade que essa relação traz em si mesma, por conta da situação de alteração que a circunscreve. $\mathrm{Na}$ feitura desse trabalho, pudemos 
vivenciar situações que não nos permitiram manter a "clássica" relação entre sujeito e objeto, aquela prevista nos livros e manuais. O trabalho, a dissertação em si, foi-se dando à medida que foram se esclarecendo as implicaçôes inerentes às relações que se estabeleceram durante o trabalho de campo. Isso significa dizer que a análise das implicações passou a ser o fio condutor do processo de construção de conhecimentón .

Cabe registrar, no entanto, que o processo de análise das implicações, como nos assinala Monceau (2008), é necessariamente um trabalho coletivo.

Eu não posso analisar minhas implicações sozinho em meu canto. Os dispositivos de análise que construímos são, pois, sempre coletivos e, geralmente, temos vários analistas em cada intervenção. Sempre presentes no trabalho de análise, podemos distinguir dois tipos de implicações, primárias e secundárias. Para simplificar, podemos dizer que nossas implicações primárias são nossas implicações dentro da própria situação de intervenção e as secundárias são nossas implicações do campo de análise. [...] Dessa forma, essa primeira abordagem da questão da implicação na situação de intervenção ... permitiu uma segunda perspectiva de intervenção ... que são as implicações dos pesquisadores na própria pesquisa. (Monceau, 2008, p. 22).

\section{O autor continua:}

[...] o trabalho do pesquisador está saturado de subjetividade. As instituições científicas vão ter suas próprias ideologias. Elas não são particularmente objetivas, mesmo se elas tentam nos fazer acreditar nisso. A questão não é que devamos nos livrar de nossas ideologias [de nossas implicações], mas tentar analisá-las coletivamente. $\mathrm{O}$ verdadeiro trabalho científico deve estar aí. (Monceau, 2008, p. 22).

Cabe resgatar ainda outro desdobramento da noção de implicação, que se revela e se constitui, na análise institucional, como uma prática política de intervenção. É sob essa dimensão que entendemos o convite de Lourau, quando ele se pergunta: "Mas, se não existe CRISE, como fazer uma análise institucional? Então dê um jeito para que ela ecloda". (Lourau, 2004a, p. 125). Através desse convite, ele nos lembra a inserção política do analista institucional, enquanto transformador da realidade social em que está inserido. Isso nos remete tanto para as dimensões políticas implícitas nas relações institucionais, como para a ação política dentro da instituição.

4 Ver Paulon (2005), que traz uma análise semelhante à que desenvolvemos aqui. 


\section{REFERÊNCIAS}

Ardoino, J. (1983). Polysémie de l'implication. Pour, 88, 19-22.

Ardoino, J. (1990). L'analyse multiréférentielle des situations sociales. Psychologie Clinique, 3, 33-49.

Ardoino, J. (2000). Les avatars de l'education: problématiques et notions en devenir. Paris: PUF.

Ardoino, J., Barbier, R., \& Giust-Desprairies, F. (1998). Entrevista com Cornelius Castoriadis. In J. G. Barbosa (Coord.). Multirreferencialidade nas ciências e na educação. (pp. 50-72).São Carlos: Editora da UFSCar.

Ardoino, J. \& Lourau, R. (1994). Les pédagogies institutionelles. Paris: PUF.

Boumard, P.; Hess, P. \& Lapassade, G. (1987). L'université en transe. Paris: Syros.

Figueiredo, L. C. M. (1991). Matrizes do pensamento psicológico. Petrópolis, RJ: Vozes.

Daumezon, G. \& Koechlin, P. (1952). Psychothérapie française institutionnelle contemporaine. Anais Portugueses de Psiquiatria, 4(4), 271-312.

Figueiredo, L. C. M. (1993). A invenção do psicológico: quatro séculos de subjetivação (1500-1900). São Paulo: Educ/Escuta.

Hammouti, N.D. El. (2002). O movimento da análise institucional, o interacionismo e a etnografia. In J. B., Martins (Org.). Temas em análise institucional e em construcionismo social. (pp. 9-96). São Carlos/Curitiba: RiMa/Fundação Araucária.

Hess, R. \& Savoye, A. (1993). L'analyse institutionelle. Paris: PUF.

Lapassade, G. \& Lourau, R. (1972). Chaves da sociologia. Rio de Janeiro: Civilização Brasileira.

Lourau, R. (1983). Genèse du concept d'implication. Pour, 88,14-18.

Lourau, R. (1996). A análise institucional. Petrópolis: Vozes. [Texto original publicado em 1970].

Lourau, R. (2004a). Pequeno manual de análise institucional. In S. Altoé (Org.). René Lourau - Analista institucional em tempo integral. (pp. 122-127). São Paulo: Hucitec. 
Lourau, R. (2004b). Implicação e sobreimplicação. In S. Altoé (Org.), René Lourau - Analista institucional em tempo integral. (pp. 186-198). São Paulo: Hucitec.

Martins, J. B. (1995). Marolas antropológicas: identidades em mudança na Praia do Santinho. Dissertação de Mestrado. Programa de Pós-Graduação em Antropologia Social. Universidade Federal de Santa Catarina.

Monceau, G. (2008). Implicação, sobreimplicação e implicação profissional. Fractal Revista de Psicologia, 20 (1), 19-26.

Paulon, S. M. A análise de implicação como ferramenta na pesquisa-intervenção. Psicologia \& Sociedade. 17(3), 18-25, 2005.

Patto, M. H. S. (1984). Psicologia e ideologia: uma introdução crítica à psicologia escolar. São Paulo: T. A. Queiroz. 